

\title{
A SHARED COMMON GOAL
}

The path to translating biological discovery into clinical testing remains ill-defined and complex. Both scientific communities share an overarching mission to improve health, but their immediate objectives are distinct. Whereas the realm of basic science seeks to elucidate biological mechanisms as a step penultimate to understanding disease, clinical trials test the

\footnotetext{
*To whom correspondence should be addressed: Matthew R. Rosengart, MD MPH, Department of Surgery, 200 Lothrop Street, Pittsburgh, PA 15213, 412-647-3065, 412-647-1448, rosengartmr@upmc.edu.

All work was performed at the University of Pittsburgh.

No reprints are requested.

Conflicts of Interest

The authors report no additional conflicts.
} 
ramifications of an intervention on the course of human disease and answer the question of effectiveness. The clinical testing of anti-tumor necrosis factor-alpha (TNF-a) agents in the 1990s makes manifest the unforeseen consequences of these differences (6). The promising results of early mechanistic studies of anti-TNFa compounds fueled an eager jump to largescale clinical trials to test this "magic bullet." However, neither the biology nor the inflammatory profile of these early studies are representative of the complex systemic host response stemming from uncontrolled infection that characterizes human sepsis (7-11). Indeed, the clinical cohorts and trial platforms by which anti-TNF compounds were tested were distinct from those that had been utilized in the lab: human subjects, varying stages of sepsis, a spectrum of causal organisms, and a randomized design $(3,7,12-20)$. When collectively viewed, the data make readily apparent that human studies were unlikely to represent the animal model upon which they were founded.

\section{THE KINETICS OF SEPSIS}

Animal studies are modeled in a manner that is inconsistent with the clinical presentation of septic patients and the design of clinical trials. Contemporary definitions of sepsis, and the biochemical and physiologic parameters from which they are derived, are perceived to represent a particular biological stage in the host response to pathogen. Yet the experimental design of animal investigation does not typically address the inherent variability and kinetics in the evolution of the host response to microbial invasion, and this provides an additional layer of consideration in modeling $(3,21,22)$. Therapies are tested at arbitrary time points after the inciting insult rather than after 'patient' presentation and fulfillment of biochemical and physiologic inclusion and exclusion criteria. Although beyond the scope of this review, these aspects become more salient as animal models of sepsis become increasingly complex with the introduction of two-hit models to better understand the later phases of sepsis where host immunity may fail to effectively counter a second challenge, or the phase of "immunosuppression" in sepsis (23). Thus, platforms that refine the physiologic and biologic assessment of experimental animal subjects enable us to better define animal correlates of distinct stages of human sepsis. This would potentially afford the ability to identify and thereby test animal cohorts possessing a profile more representative of the human subjects enrolled in clinical research. This imperative possesses a clinical correlate, insofar that enhanced measures of endotyping human subjects may smooth the stepwise progression from basic to clinical investigation.

\section{THE APPLICATION OF CONSORT TO ANIMAL MODELS}

Animal models test mechanistic queries upon a reductionist experimental platform that ensures causality is accurately addressed. Assuring causality is paramount, and thus the model is predicated upon holding all other recognized events constant to eliminate the obfuscation that originates from heterogeneity. It is from this approach that biological mechanisms are characterized and integrated into contemporary biological paradigms of sepsis. However, once a potential therapeutic target has been identified, the actual testing of agents in pre-clinical animal models, an important translational step prior to clinical trial, should proceed differently. 


\section{Study Design}

A fundamental assumption of hypothesis testing is chance, and chance is better assured with randomization and blinding. Although there are limitations to the randomized, controlled trial (RCT) and no study is flawless, a well-designed double-blind, placebo controlled RCT remains a gold standard of testing (24). If executed correctly, it eliminates bias and relegates the resultant data to one of two interpretations: 1) chance or 2) a rejection of the null hypothesis (25). Although there is growing recognition for enhancing rigor and reproducibility, many animal-based studies are not powered a priori (i.e., sample size estimates) for a primary endpoint, nor do they randomize animal subjects to an intervention or blind the investigators and those analyzing the resultant data (26).

Clinical trials are 'powered' to optimize the statistical ability to identify an a priori chosen effect size for the primary outcome of interest. Power is dependent upon 1) the magnitude of the between-group difference in means and 2) the standard error of the mean (SEM), which is a function of the sample size. Insufficient sampling or too small of an effect size enhance the risk of a type II error (failure to reject the null hypothesis when the alternate hypothesis is true; a false negative), and a potential therapeutic is never brought to clinical reality (27).

Cognizance of a type I (erroneously rejecting the null hypothesis when in fact it is true; a false positive) must also be exercised (27). The data yielded from basic science serve as the impetus for subsequent clinical testing. Potential sources of bias (e.g., not blinding) that foster a 'positive' study may erroneously support a false perception of success and the conduct of a clinical trial that consumes resources unnecessarily and exposes human subjects to risk. An example is randomizing an entire box of mice to an intervention but analyzing at the individual animal level; animals of the same cage are not independent and may possess characteristics rendering them unique relative to animals of other cages. The lack of independence artificially narrows the standard error and supports a type I error, whereas the latter may confound the results. Ideally, randomization of individual mice by sex, age, and in some cases, strain to an intervention should occur in addition to the blinding of the investigators performing the experimentation and data interpretation.

\section{Subjects and the model itself}

The vast majority of animal laboratories utilize rodent models (3). The genetic homology is substantial (approximately $80 \%$ of mouse genes possess an identifiable orthologue in humans), and when combined with the expansive techniques for genetic manipulation, renders the mouse a powerful tool for dissecting the biological mechanisms of mammalian life (28-30). Important distinctions still persist, which too have undermined translation of discovery to human disease $(31,32)$. For example, rodents are more robust and resilient to septic insult, and the mismatch between severity of the experimental model and that of the clinical disease may further distance the two.

Overcoming these limitations can be achieved, in part, by sequentially progressing into larger animal models. Determining 'when' and 'how' are difficult decisions that likely depend upon the question that is being addressed, the complexity of the disease studied and its biology (33). However, survival studies in large animals may pose ethical dilemmas, are 
costly and resource-intensive, and yield small sample sizes, thereby rendering statistical inference challenging (3). Thus, prior to advancing to higher ordered species, rodent models are useful when they closely approximate the human disease for which therapy is being developed. Premature testing of anti-TNFa therapy in non-human primate models of endotoxemia may have yielded 'promising' results, whereas rodent models (i.e., CLP) more closely mirroring the sepsis of humans (i.e., intraabdominal catastrophe of perforated diverticulitis) may have highlighted the futility of such higher ordered experimentation, thereby sparing time, money, and importantly animals. This attention to model relevance includes an appreciation for the microbial epidemiology of a disease.

The majority of cohorts enrolled in clinical trials of sepsis are comprised of men and women, of older age, who possess a spectrum of comorbidities. Yet most basic laboratory investigation has used juvenile mice (8-12 weeks) that are healthy and typically of a single sex and strain. The process of aging is characterized by profound changes in immunity, and several studies highlight that aged mice exhibit vastly different biology than younger counterparts $(34,35)$. Indeed, most prior studies testing immunomodulatory agents used mice that did not approximate the age of the typical, adult patient populations presenting for sepsis care. The same biological heterogeneity has been observed when comparing different strains, gender and outbred mice $(36,37,34,38-41)$. Similarly, the presence or absence of comorbidities significantly influences the trajectory and outcome of sepsis and has been difficult to, and thus infrequently, replicated in murine models (42). However genetically modified mice that exhibit many of the comorbidities of our aging population are commercially available, and their increased use may foster successful translation.

It is beyond the scope of this discourse to discuss the innumerable permutations of animal models of sepsis (Table 1) or the obvious fact that not all sepsis is equal. Investigations aimed at dissecting biological mechanisms typically adopt a reductionist approach: the use of microbial components (e.g., lipopolysaccharide) and genetic manipulation of cognate receptors (e.g., toll-like receptor TLR-4) to understand the biological ramifications on host inflammation and survival. Yet, as was observed with anti-TNF compounds and most recently TLR4 antagonists, these studies, though biologically insightful, may yield disappointment when subsequent clinical trials fail to determine efficacy $(6,43)$. The model of 'sepsis' itself also influences the degree to which the results predict future success of human testing. For example, certain models such as CLP approximate human disease better than endotoxemia (44-46). The breadth of variability (i.e., puncture size and number, length of ligation) facilitates standardizing the model to a particular severity $(22,46-49)$. Contemporary advocates of re-exploration for removal of the necrotic cecal segment and source control note the closer approximation to clinical care; however, this additional step has not been broadly practiced $(45,46,50-55)$. Similarly, the colon ascendens stent peritonitis model attempts to recreate the conditions of a free perforated viscus with diffuse peritonitis, and proponents argue to its greater clinical relevance to actual disease $(56,57)$. The same can be said for the other predominant forms of sepsis for which clinicians provide care: urinary tract infections and pneumonia. Logically the more closely the animal model resembles the disease situation, the more likely relevant the data will be that is generated from them. 
Standardizing animal models may also facilitate ease of data interpretation and afford opportunities to apply Bayesian and meta-analyses (58). To that end, some investigators have called for the development of standard murine sepsis models. One such effort is the "Minimum Quality Threshold in Pre-clinical Sepsis Studies" (MQTiPSS), which aims to produce a standard murine model of intraabdominal sepsis (59). Adding guidance specifying when and how to progress to higher vertebrate models would generate an instructional manual of step-wise translational experimentation performed with the intent of optimizing the 'success' of subsequent clinical trials.

\section{Enrollment and the testing of interventions}

Enrollment for clinical trials is guided by physiologic and biochemical inclusion and exclusion criteria that presumably reflect a particular biological stage in the host response to uncontrolled infection (3). For example, inclusion criteria may include all subjects 18 years or older with definitive microbiological or clinical evidence of acute infection, hypothermia or hyperthermia, tachycardia, tachypnea, and hypotension or other evidence of end-organ dysfunction. Exclusion criteria may include immunocompromised state and anticipated survival < 48 hours (60). Rarely are such parameters applied to murine studies, and their absence may serve as one barrier to successful translation.

Animal models administer and test interventions at fixed time intervals after the inciting insult (e.g., cecal puncture). This approach may not account for the inherent variability in magnitude and temporality of the animal's response to sepsis. At any specific time, only a fraction of the animals may be at a particular biological stage (61). In this 21-gauge, double puncture model of CLP (Figure 1), testing at a 12-hour timepoint would include $n=6$ mice with no physiologic evidence (i.e., hypothermia, bradycardia) of sepsis. Even at 24 hours after CLP, these 6 mice exhibit little physiologic evidence of sepsis and may not have met the inclusion criteria of a clinical trial (60). Consequently animals are being 'enrolled' and tested at very different points in the biological response to sepsis (Figure 1), and salient to human trials that often use physiologic triggers to administer new treatments, murine models incorporating solely fixed schedules may show less clinical relevance $(3,21,52)$.

Recent efforts are refining the platform of animal experimentation, the assessment of the kinetics of the septic animal, and enabling the identification of phenotypes that represent biological stages in the evolution of the host response to pathogen. The murine sepsis score (MSS), a scale comprised of seven behavioral and physical characteristics was developed to enable the prediction of shock and death, a better comparison of disease and treatment outcomes in animal models of sepsis, and provide a murine correlate of the sophisticated scoring systems applied in human illness: APACHEII and SOFA (Table 2) (62-64). Using a dose-response cecal slurry model, the developers reported moderately strong discriminatory power for survival, organ injury and cytokine concentrations and excellent inter-rater reliability. A similar score has been developed for Klebsiella pneumoniae pneumonia: the mouse clinical assessment for sepsis (M-CASS) (63). A notable limitation is the use of a single strain (C57BL/6J) of mice that were young (8-12 weeks). The MSS also utilized a single sex (male) (63). Resolution remains dependent on the frequency of mouse scoring, which can introduce bias from handling (65). Nevertheless, the MSS and M-CASS are 
perceived to advance the status quo, facilitating the separation of mice that are significantly ill from those that are not.

Implantable wireless biotelemetry has enabled the development of a physiology-oriented murine model $(20,66-76)$. Coupled with CLP, biotelemetry can help quantify physiologic differences in the murine response to sepsis that are indicative of significant biological differences. The model more precisely identifies a similar point along the spectrum of the host response to sepsis for each animal, independent of lapsed time after the insult. In doing so, it yields a more homogeneous cohort of testable mice at a similar physiologic state and accurately excludes mice that do not meet physiologic inclusion criteria. A follow-up study validated the platform in female and male, young (12 week) and aged (40-50 week), and different strains (C57BL/6J, BALB/C) of mice. Furthermore, the model possesses face validity in enabling real-time physiologic assessment in more complex (e.g., 2-hit models) models and studying later phases of sepsis where it may be even more important to assess individual animal responses. The authors quantified the reduced animal usage and potential ethical benefits in addressing the 3 R's (Replacement, Reduction, and Refinement) first proposed in the Principles of Humane Experimental Technique (77-81). A notable limitation is cost, yet the investigators provide a cost analysis of incorporating the technology into laboratory practice.

\section{Reporting in Animal Trials}

Efforts to standardize protocol development and the reporting of results of human trials have been promulgated by the SPIRIT (Standard Protocol Items: Recommendations for Interventional Trials) and CONSORT (Consolidated Standards of Reporting Trials) statements $(82,83)$. Historically the platform of animal-based investigation has lacked this principled approach (26). The recently developed ARRIVE (Animal Research: Reporting In Vivo Experiments) guidelines offer a similar framework for standardizing the conduct and quality reporting of animal studies (79). Nearly every point on the ARRIVE checklist has a recognizable analogue in the CONSORT checklist (Table 3 ). While adopted by many journals, utilization of the ARRIVE guidelines still have room for improvement (84). Perhaps a greater adoption of ARRIVE by basic scientists will facilitate disseminating fundamental quality metrics of animal research. The corollary is equally valid, however; attention by basic scientists to the CONSORT statements of clinical trials may facilitate reverse translation into basic investigation.

Adding biology to human clinical trials-The exchange of data and ideas is bidirectional, and the concept of "reverse translation" emphasizes that we can bring clinical observations back into the laboratory for further study $(85,86)$. The initial trials of gefitinib targeting the epidermal growth factor receptor (EGFR) revealed only modest benefit in the treatment of lung cancer $(87,88)$. Posthoc analyses, however noted that gefitinib conferred a survival benefit for particular subgroups (89). Laboratory investigators, convinced that these unique sub-cohorts experiencing benefit shared a common biological feature, performed mutational testing on tumor specimens from enrolled subjects. They determined that patients with particular somatic mutations in EGFR obtained benefit from the drug (89). Had this reverse translation not occurred, the overall conclusion for the utility of the drug in question 
would have been dramatically different, and many patients may have lost the potential benefit afforded by gefitinib (90).

Despite inclusion and exclusion criteria, the populations of clinical trials still possess heterogeneity at the biological level. The resultant variability, many argue, is another principle factor underlying the high prevalence of negative trials of sepsis. Recent trials underscore the potentially profound ramifications when the biological mechanisms characterized through basic investigation and that guided drug development are incorporated. The Monoclonal Anti-TNF: A Randomized Controlled Sepsis (MONARCS) study continued the testing of anti-TNF compounds, however, stratified subjects by base-line serum IL-6 concentrations (60). The design strategy stemmed, in part, from basic science demonstrating that IL-6, which is released in response to TNFa and IL-1, is consistently detected in the blood of patients with sepsis, and elevated levels are associated with adverse outcome. Thus, an intermediary hypothesis is that elevated IL-6 concentrations may be useful in identifying those patients most likely to benefit from anti-TNFa therapy. This perspective is supported by animal-based investigation validating that early quantification of IL-6 concentration stratifies low- and high-risk outcomes, reduces heterogeneity and refines selection for therapy (91). In the overall population $(n=2634)$ there was no significant difference in 28-day mortality for placebo and afelimomab groups (35.9\% and 32.3\%). However, in the cohort with elevated IL-6, the adjusted 28-day mortality was reduced with anti-TNFa therapy: adjusted absolute reduction in mortality $5.8 \%(\mathrm{p}=0.041)(60)$. More recent meta-analyses now support anti-TNF compounds (92). Thus, circumstances in which clinical trials are 'brought closer' to the murine models upon which they are based may help illuminate the path between the basic and clinical sciences.

\section{CONCLUSION}

The translational divide between the basic laboratory and clinical research realms persists yet cannot be ignored if we are to capitalize upon the wealth of biologic discovery and our ever-growing knowledge to develop novel sepsis therapeutics that beneficially alter human disease. The scientific community must continue discourse and action that standardize methodologies, develop more clinically analogous and relevant laboratory research platforms, enhance the reporting and dissemination of research findings, and incorporate biologic mechanisms into the design of clinical trials. It is the bridging of these two impressive worlds that is needed.

\section{Acknowledgments}

We wish to acknowledge the contribution of John E. Griepentrog, MD to the manuscript preparation and revision.

Sources of Funding:

Financial support was provided by a Basic/Translational Research Training Fellowship Grant awarded by the Surgical Infection Society (MRR), R01 GM082852 (MRR), R01 GM116929 (MRR), R01 HL086884 (JSL), R01 HL136143 (JSL), and T32GM008516 (AJL).

Copyright form disclosure: All authors received support for article research from the National Institutes of Health. 


\section{References}

1. Angus DC, Linde-Zwirble WT, Lidicker J, et al. Epidemiology of severe sepsis in the United States: analysis of incidence, outcome, and associated costs of care. Crit Care Med. 2001; 29:1303-1310. [PubMed: 11445675]

2. Ranieri VM, Thompson BT, Barie PS, et al. Drotrecogin alfa (activated) in adults with septic shock. N Engl J Med. 2012; 366:2055-64. [PubMed: 22616830]

3. Fink MP. Animal models of sepsis. Virulence. 2014; 5:143-153. [PubMed: 24022070]

4. Bernard GR, Vincent JL, Laterre PF, et al. Efficacy and safety of recombinant human activated protein C for severe sepsis. N Engl J Med. 2001; 344:699-709. [PubMed: 11236773]

5. Abraham E, Laterre P-F, Garg R, et al. Drotrecogin alfa (activated) for adults with severe sepsis and a low risk of death. N Engl J Med. 2005; 353:1332-41. [PubMed: 16192478]

6. Marshall JC, Deitch E, Moldawer LL, et al. Preclinical models of shock and sepsis: what can they tell us? Shock. 2005; 24(Suppl 1):1-6. [PubMed: 16374365]

7. Eskandari MK, Bolgos G, Miller C, et al. Anti-tumor necrosis factor antibody therapy fails to prevent lethality after cecal ligation and puncture or endotoxemia. J Immunol. 1992; 148:2724-30. [PubMed: 1315357]

8. van Eijk LTGJ, Pickkers P, Smits P, et al. Microvascular permeability during experimental human endotoxemia: an open intervention study. Crit Care. 2005; 9:R157-64. [PubMed: 15774049]

9. Deitch EA. Animal models of sepsis and shock: a review and lessons learned. Shock. 1998; 9:1-11.

10. Buras JA, Holzmann B, Sitkovsky M. Animal models of sepsis: setting the stage. Nat Rev Drug Discov. 2005; 4:854-65. [PubMed: 16224456]

11. Remick DG, Newcomb DE, Bolgos GL, et al. Comparison of the mortality and inflammatory response of two models of sepsis: lipopolysaccharide vs. cecal ligation and puncture. Shock. 2000; 13:110-116. [PubMed: 10670840]

12. Gallagher J, Fisher C, Sherman B, et al. A multicenter, open-label, prospective, randomized, doseranging pharmacokinetic study of the anti-TNF-alpha antibody afelimomab in patients with sepsis syndrome. Intensive Care Med. 2001; 27:1169-78. [PubMed: 11534565]

13. Cohen J, Carlet J. INTERSEPT: an international, multicenter, placebo-controlled trial of monoclonal antibody to human tumor necrosis factor-alpha in patients with sepsis. International Sepsis Trial Study Group. Crit Care Med. 1996; 24:1431-40. [PubMed: 8797612]

14. Abraham E, Anzueto A, Gutierrez G, et al. Double-blind randomised controlled trial of monoclonal antibody to human tumour necrosis factor in treatment of septic shock. NORASEPT II Study Group. Lancet (London, England). 1998; 351:929-33.

15. Abraham E, Wunderink R, Silverman H, et al. Efficacy and safety of monoclonal antibody to human tumor necrosis factor alpha in patients with sepsis syndrome. A randomized, controlled, double-blind, multicenter clinical trial. TNF-alpha MAb Sepsis Study Group. JAMA. 273:934-41.

16. Qiu P, Cui X, Sun J, et al. Antitumor necrosis factor therapy is associated with improved survival in clinical sepsis trials: a meta-analysis. Crit Care Med. 2013; 41:2419-29. [PubMed: 23887234]

17. Fisher CJ, Agosti JM, Opal SM, et al. Treatment of septic shock with the tumor necrosis factor receptor:Fc fusion protein. The Soluble TNF Receptor Sepsis Study Group. N Engl J Med. 1996; 334:1697-702. [PubMed: 8637514]

18. Rittirsch D, Hoesel LM. The disconnect between animal models of sepsis and human sepsis. J Leukoc Biol. 2007; 81:137-143. [PubMed: 17020929]

19. Martin RA, Silva AT, Cohen J. Effect of anti-TNF-alpha treatment in an antibiotic treated murine model of shock due to Streptococcus pyogenes. FEMS Microbiol Lett. 1993; 110:175-8.

[PubMed: 8349091]

20. Remick D, Manohar P, Bolgos G, et al. Blockade of tumor necrosis factor reduces lipopolysaccharide lethality, but not the lethality of cecal ligation and puncture. Shock. 1995; 4:89-95. [PubMed: 7496903]

21. Lewis AJ, Yuan D, Zhang X, et al. Use of Biotelemetry to Define Physiology-Based Deterioration Thresholds in a Murine Cecal Ligation and Puncture Model of Sepsis. Crit Care Med. 2016; 44:e420-31. [PubMed: 26862708] 
22. Lewis AJ, Seymour CW, Rosengart MR. Current Murine Models of Sepsis. Surg Infect (Larchmt). 2016; 17:385-93. [PubMed: 27305321]

23. Boomer JS, To K, Chang KC, et al. Immunosuppression in patients who die of sepsis and multiple organ failure. JAMA. 2011; 306:2594-605. [PubMed: 22187279]

24. Frieden TR. Evidence for Health Decision Making - Beyond Randomized, Controlled Trials. N Engl J Med. 2017; 377:465-475. [PubMed: 28767357]

25. Peto R, Pike MC, Armitage $P$, et al. Design and analysis of randomized clinical trials requiring prolonged observation of each patient. I Introduction and design. Br J Cancer. 1976; 34:585-612. [PubMed: 795448]

26. Han S, Olonisakin TF, Pribis JP, et al. A checklist is associated with increased quality of reporting preclinical biomedical research: A systematic review. PLoS One. 2017; 12:e0183591. [PubMed: 28902887]

27. Akobeng AK. Understanding type I and type II errors, statistical power and sample size. Acta Paediatr. 2016; 105:605-9. [PubMed: 26935977]

28. Osuchowski MF, Remick DG, Lederer JA, et al. Abandon the Mouse Research Ship? Not Just Yet! Shock. 2014; 41:463-475. [PubMed: 24569509]

29. Takao K, Miyakawa T. Genomic responses in mouse models greatly mimic human inflammatory diseases. Proc Natl Acad Sci. 2015; 112:1167-1172. [PubMed: 25092317]

30. Mouse Genome Sequencing Consortium. Waterston RH, Lindblad-Toh K, et al. Initial sequencing and comparative analysis of the mouse genome. Nature. 2002; 420:520-62. [PubMed: 12466850]

31. Cordle F, Miller SA. Using epidemiology to regulate food additives: saccharin case-control studies. Public Health Rep. 99:365-9. [PubMed: 6431484]

32. Seok J, Warren HS, Cuenca AG, et al. Genomic responses in mouse models poorly mimic human inflammatory diseases. Proc Natl Acad Sci U S A. 2013; 110:3507-12. [PubMed: 23401516]

33. Rhesus Macaque Genome Sequencing and Analysis Consortium. Gibbs RA, Rogers J, et al. Evolutionary and biomedical insights from the rhesus macaque genome. Science. 2007; 316:22234. [PubMed: 17431167]

34. Turnbull IR, Clark AT, Stromberg PE, et al. Effects of aging on the immunopathologic response to sepsis. Crit Care Med. 2009; 37:1018-23. [PubMed: 19237912]

35. Starr ME, Ueda J, Takahashi H, et al. Age-dependent vulnerability to endotoxemia is associated with reduction of anticoagulant factors activated protein $\mathrm{C}$ and thrombomodulin. Blood. 2010; 115:4886-93. [PubMed: 20348393]

36. Saito H, Sherwood ER, Varma TK, et al. Effects of aging on mortality, hypothermia, and cytokine induction in mice with endotoxemia or sepsis. Mech Ageing Dev. 2003; 124:1047-1058. [PubMed: 14659593]

37. Turnbull IR, Wlzorek JJ, Osborne D, et al. Effects of age on mortality and antibiotic efficacy in cecal ligation and puncture. Shock. 2003; 19:310-3. [PubMed: 12688540]

38. Howell GM, Gomez H, Collage RD, et al. Augmenting autophagy to treat acute kidney injury during endotoxemia in mice. PLoS One. 2013; 8:e69520. [PubMed: 23936035]

39. Iskander KN, Craciun FL, Stepien DM, et al. Cecal ligation and puncture-induced murine sepsis does not cause lung injury. Crit Care Med. 2013; 41:159-70. [PubMed: 23222255]

40. Doerschug KC, Powers LS, Monick MM, et al. Antibiotics delay but do not prevent bacteremia and lung injury in murine sepsis. Crit Care Med. 2004; 32:489-94. [PubMed: 14758168]

41. Bhargava R, Altmann CJ, Andres-Hernando A, et al. Acute lung injury and acute kidney injury are established by four hours in experimental sepsis and are improved with pre, but not post, sepsis administration of TNF-alpha antibodies. PLoS One. 2013; 8:1-11.

42. Wang HE, Shapiro NI, Griffin R, et al. Chronic medical conditions and risk of sepsis. PLoS One. 2012; 7:e48307. [PubMed: 23118977]

43. Opal SM, Laterre P-F, Francois B, et al. Effect of eritoran, an antagonist of MD2-TLR4, on mortality in patients with severe sepsis: the ACCESS randomized trial. JAMA. 2013; 309:115462. [PubMed: 23512062]

44. Wichterman KA, Baue AE, Chaudry IH. Sepsis and septic shock-a review of laboratory models and a proposal. J Surg Res. 1980; 29:189-201. [PubMed: 6997619] 
45. Baker CC, Chaudry IH, Gaines HO, et al. Evaluation of factors affecting mortality rate after sepsis in a murine cecal ligation and puncture model. Surgery. 1983; 94:331-5. [PubMed: 6879447]

46. Hubbard WJ, Choudhry M, Schwacha MG, et al. Cecal ligation and puncture. Shock. 2005; 24:5257. [PubMed: 16374373]

47. Singleton KD, Wischmeyer PE. Distance of cecum ligated influences mortality, tumor necrosis factor-alpha and interleukin-6 expression following cecal ligation and puncture in the rat. Eur Surg Res. 2003; 35:486-91. [PubMed: 14593232]

48. Ruiz S, Vardon-Bounes F, Merlet-Dupuy V, et al. Sepsis modeling in mice: ligation length is a major severity factor in cecal ligation and puncture. Intensive care Med Exp. 2016; 4:22. [PubMed: 27430881]

49. Otero-Antón E, González-Quintela A, López-Soto A, et al. Cecal ligation and puncture as a model of sepsis in the rat: influence of the puncture size on mortality, bacteremia, endotoxemia and tumor necrosis factor alpha levels. Eur Surg Res. 2001; 33:77-9. [PubMed: 11399872]

50. Remick DG, Bolgos GR, Siddiqui J, et al. Six at six: interleukin- 6 measured $6 \mathrm{~h}$ after the initiation of sepsis predicts mortality over 3 days. Shock. 2002; 17:463-467. [PubMed: 12069181]

51. Nakagawa NK, Jukemura J, Aikawa P, et al. In vivo observation of mesenteric leukocyteendothelial interactions after cecal ligation/puncture and surgical sepsis source control. Clinics (Sao Paulo). 2007; 62:321-6. [PubMed: 17589674]

52. Poli-de-Figueiredo LF, Garrido AG, Nakagawa N, et al. Experimental models of sepsis and their clinical relevance. Shock. 2008; 30(Suppl 1):53-59. [PubMed: 18704008]

53. Xiao H, Siddiqui J, Remick DG. Mechanisms of mortality in early and late sepsis. Infect Immun. 2006; 74:5227-5235. [PubMed: 16926416]

54. Kuethe JW, Midura EF, Rice TC, et al. Peritoneal wash contents used to predict mortality in a murine sepsis model. J Surg Res. 2015:1-9.

55. Alverdy JC, Krezalek MA. Collapse of the Microbiome, Emergence of the Pathobiome, and the Immunopathology of Sepsis. Crit Care Med. 2017; 45:337-347. [PubMed: 28098630]

56. Zantl N, Uebe A, Neumann B, et al. Essential role of gamma interferon in survival of colon ascendens stent peritonitis, a novel murine model of abdominal sepsis. Infect Immun. 1998; 66:2300-9. [PubMed: 9573121]

57. Maier S, Traeger T, Entleutner M, et al. Cecal ligation and puncture versus colon ascendens stent peritonitis: two distinct animal models for polymicrobial sepsis. Shock. 2004; 21:505-511. [PubMed: 15167678]

58. Dyson A, Singer M. Animal models of sepsis: why does preclinical efficacy fail to translate to the clinical setting? Crit Care Med. 2009; 37:S30-7. [PubMed: 19104223]

59. Osuchowski MF, Thiemermann C, Remick DG. Sepsis-3 on the Block: What Does It Mean for Preclinical Sepsis Modeling? Shock. 2017; 47:658-660. [PubMed: 28410332]

60. Panacek EA, Marshall JC, Albertson TE, et al. Efficacy and safety of the monoclonal anti-tumor necrosis factor antibody F(ab')2 fragment afelimomab in patients with severe sepsis and elevated interleukin-6 levels. Crit Care Med. 2004; 32:2173-82. [PubMed: 15640628]

61. Iskander KN, Osuchowski MF, Stearns-Kurosawa DJ, et al. Sepsis: multiple abnormalities, heterogeneous responses, and evolving understanding. Physiol Rev. 2013; 93:1247-88. [PubMed: 23899564]

62. Shrum B, Anantha RV, Xu SX, et al. A robust scoring system to evaluate sepsis severity in an animal model. BMC Res Notes. 2014; 7:233. [PubMed: 24725742]

63. Huet O, Ramsey D, Miljavec S, et al. Ensuring animal welfare while meeting scientific aims using a murine pneumonia model of septic shock. Shock. 2013; 39:488-94. [PubMed: 23603767]

64. Humane endpoints in shock research. Shock. 2004; 21:17-25. [PubMed: 14676679]

65. Kort WJ, Hekking-Weijma JM, TenKate MT, et al. A microchip implant system as a method to determine body temperature of terminally ill rats and mice. Lab Anim. 1998; 32:260-269. [PubMed: 9718473]

66. Doi K, Hu X, Yuen PST, et al. AP214, an analogue of alpha-melanocyte-stimulating hormone, ameliorates sepsis-induced acute kidney injury and mortality. Kidney Int. 2008; 73:1266-1274. [PubMed: 18354376] 
67. Schuerholz T, Doemming S, Hornef M, et al. The anti-inflammatory effect of the synthetic antimicrobial peptide 19-2.5 in a murine sepsis model: a prospective randomized study. Crit Care. 2013; 17:R3. [PubMed: 23302299]

68. Zanotti-Cavazzoni SL, Guglielmi M, Parrillo JE, et al. Fluid resuscitation influences cardiovascular performance and mortality in a murine model of sepsis. Intensive Care Med. 2009; 35:748-754. [PubMed: 19066851]

69. Nandi M, Kelly P, Torondel B, et al. Genetic and pharmacological inhibition of dimethylarginine dimethylaminohydrolase 1 is protective in endotoxic shock. Arterioscler Thromb Vasc Biol. 2012; 32:2589-2597. [PubMed: 22995517]

70. Remick DG, Call DR, Ebong SJ, et al. Combination immunotherapy with soluble tumor necrosis factor receptors plus interleukin 1 receptor antagonist decreases sepsis mortality. Crit Care Med. 2001; 29:473-481. [PubMed: 11373406]

71. Blockade or deletion of transient receptor potential vanilloid 4 (TRPV4) is not protective in a murine model of sepsis [Internet]. F1000Research. 2015; 4 Available from: http:// f1000research.com/articles/4-93/v1.

72. Xiao H, Remick DG. Correction of perioperative hypothermia decreases experimental sepsis mortality by modulating the inflammatory response. Crit Care Med. 2005; 33:161-167. [PubMed: 15644664]

73. Ganopolsky JG, Castellino FJ. A protein C deficiency exacerbates inflammatory and hypotensive responses in mice during polymicrobial sepsis in a cecal ligation and puncture model. Am $\mathrm{J}$ Pathol. 2004; 165:1433-1446. [PubMed: 15466407]

74. Souza LL, Duchene J, Todiras M, et al. Receptor MAS protects mice against hypothermia and mortality induced by endotoxemia. Shock. 2014; 41:331-6. [PubMed: 24430551]

75. Remick DG, Garg SJ, Newcomb DE, et al. Exogenous interleukin-10 fails to decrease the mortality or morbidity of sepsis. Crit Care Med. 1998; 26:895-904. [PubMed: 9590320]

76. Newcomb D, Bolgos G, Green L, et al. Antibiotic treatment influences outcome in murine sepsis: mediators of increased morbidity. Shock. 1998; 10:110-117. [PubMed: 9721977]

77. Russell W, Burch R. The principles of humane experimental technique. London: Methuen \& Co; 1959.

78. Lloyd MH, Foden BW, Wolfensohn SE. Refinement: promoting the three Rs in practice. Lab Anim. 2008; 42:284-93. [PubMed: 18625583]

79. Kilkenny C, Browne WJ, Cuthill IC, et al. Improving bioscience research reporting: the ARRIVE guidelines for reporting animal research. PLoS Biol. 2010; 8:e1000412. [PubMed: 20613859]

80. Lewis A, Zuckerbraun B, Griepentrog J, et al. Reducing Animal Use with a BiotelemetryEnhanced Murine Model of Sepsis. Sci Rep. 2017; 7:6622. [PubMed: 28747734]

81. Lewis AJ, Griepentrog JE, Zhang X. , et al. Prompt Administration of Antibiotics and Fluids in the Treatment of Sepsis: A Murine Trial. [Internet]. Crit Care Med. 2018. Available from: http:// www.ncbi.nlm.nih.gov/pubmed/29369056

82. Chan A-W, Tetzlaff JM, Altman DG, et al. SPIRIT 2013 statement: defining standard protocol items for clinical trials. Ann Intern Med. 2013; 158:200-7. [PubMed: 23295957]

83. Schulz KF, Altman DG, Moher D, et al. CONSORT 2010 statement: updated guidelines for reporting parallel group randomised trials. BMJ. 2010; 340:c332. [PubMed: 20332509]

84. Baker D, Lidster K, Sottomayor A, et al. Two years later: journals are not yet enforcing the ARRIVE guidelines on reporting standards for pre-clinical animal studies. PLoS Biol. 2014; 12:e1001756. [PubMed: 24409096]

85. The future of murine sepsis and trauma research models. J Leukoc Biol. 2015; 98:1-8. [PubMed: 26130765]

86. Rubio DM, Schoenbaum EE, Lee LS, et al. Defining translational research: implications for training. Acad Med. 2010; 85:470-5. [PubMed: 20182120]

87. Kris MG, Natale RB, Herbst RS, et al. Efficacy of gefitinib, an inhibitor of the epidermal growth factor receptor tyrosine kinase, in symptomatic patients with non-small cell lung cancer: a randomized trial. JAMA. 2003; 290:2149-58. [PubMed: 14570950] 
88. Fukuoka M, Yano S, Giaccone G, et al. Multi-institutional randomized phase II trial of gefitinib for previously treated patients with advanced non-small-cell lung cancer (The IDEAL 1 Trial) [corrected]. J Clin Oncol. 2003; 21:2237-46. [PubMed: 12748244]

89. Lynch TJ, Bell DW, Sordella R, et al. Activating mutations in the epidermal growth factor receptor underlying responsiveness of non-small-cell lung cancer to gefitinib. N Engl J Med. 2004; 350:2129-39. [PubMed: 15118073]

90. Mitsudomi T, Morita S, Yatabe Y, et al. Gefitinib versus cisplatin plus docetaxel in patients with non-small-cell lung cancer harbouring mutations of the epidermal growth factor receptor (WJTOG3405): an open label, randomised phase 3 trial. Lancet Oncol. 2010; 11:121-8. [PubMed: 20022809]

91. Osuchowski MF, Connett J, Welch K, et al. Stratification is the key: inflammatory biomarkers accurately direct immunomodulatory therapy in experimental sepsis. Crit Care Med. 2009; 37:1567-1573. [PubMed: 19325479]

92. Lv S, Han M, Yi R, et al. Anti-TNF-a therapy for patients with sepsis: a systematic meta-analysis. Int J Clin Pract. 2014; 68:520-8. [PubMed: 24548627] 


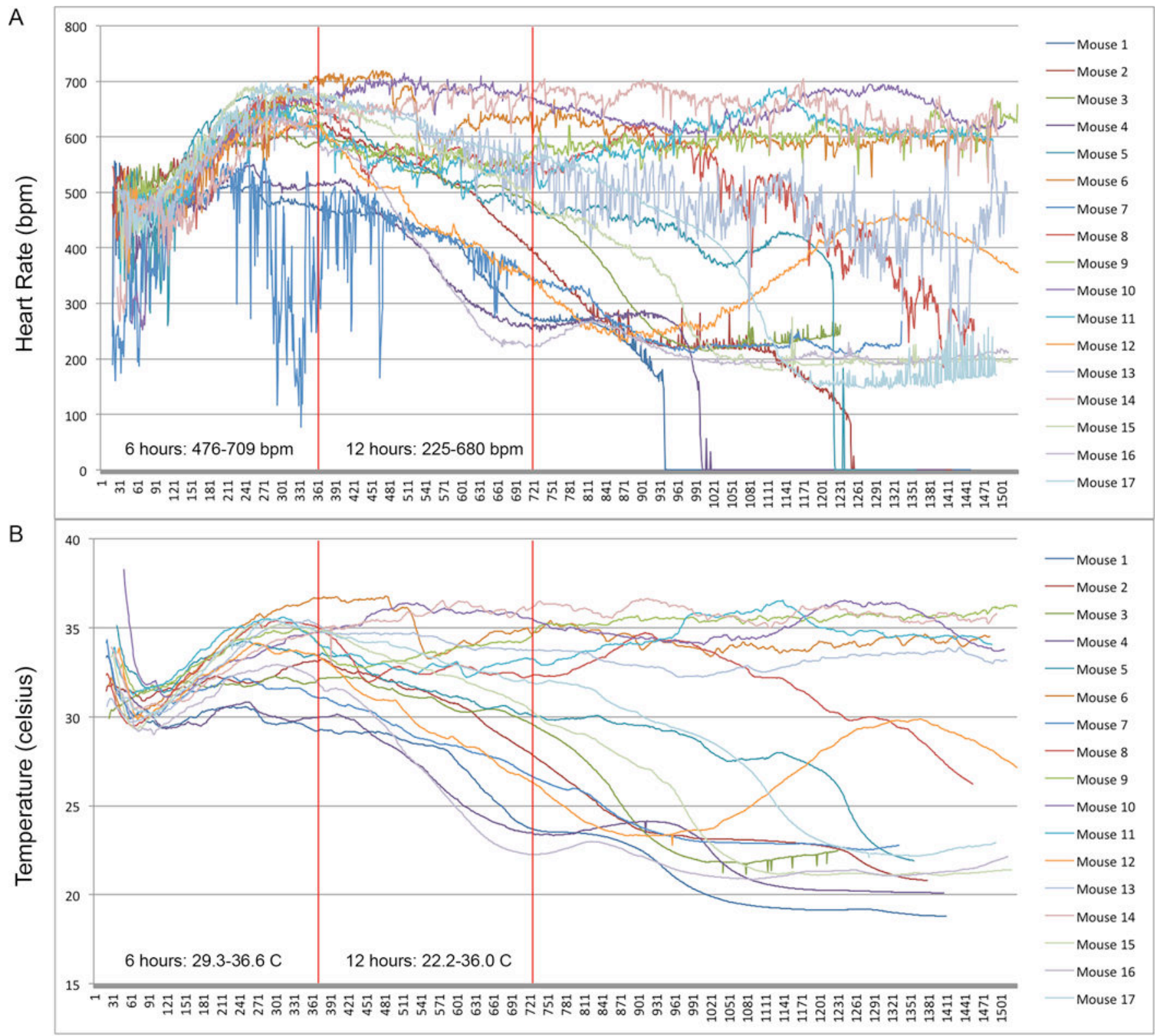

Time after CLP(minutes)

Figure 1. Physiology early after CLP: heart rate and core temperature

C57BL/6 mice underwent laparotomy, CLP, and implantation of a DSI HD-X11 telemetry device and were then monitored for 24 hours or until death. A, Heart rate. B, Core temperature. Each line represents a single mouse $(n=17)$. Vertical red lines represent time points 6 and 12 hours after CLP. 


\section{Table 1}

\section{Experimental Murine Sepsis Models and their Clinical Analogues}

\begin{tabular}{lll}
\hline Model & Technique & Clinical Analogue \\
\hline Lipopolysaccharide injection & $\begin{array}{l}\text { Injection of LPS into the peritoneal cavity or } \\
\text { bloodstream }\end{array}$ & $\begin{array}{l}\text { None, although it may resemble fulminant } \\
\text { meningococcemia in some cases }\end{array}$ \\
Bacterial injection & $\begin{array}{l}\text { Injection of bacteria in the peritoneal cavity or } \\
\text { bloodstream }\end{array}$ & $\begin{array}{l}\text { None. Lacks the constant source of bacteria } \\
\text { characteristic of human sepsis and instead } \\
\text { administers a single bolus }\end{array}$ \\
Cecal slurry & $\begin{array}{l}\text { Injection of a standard amount of donor mouse cecal } \\
\text { contents into the peritoneal cavity }\end{array}$ & $\begin{array}{l}\text { Perforated viscus, though it lacks a continuous } \\
\text { source of contamination }\end{array}$ \\
Cecal ligation and puncture & $\begin{array}{l}\text { Ligation of a specified portion of the cecum then } \\
\text { cecal puncture and extrusion of contents }\end{array}$ & $\begin{array}{l}\text { Perforated diverticulitis or appendicitis with } \\
\text { abscess formation }\end{array}$ \\
Colon ascendens stent peritonitis & $\begin{array}{l}\text { Insertion of a stent into the ascending colon with } \\
\text { continuous flow of stool into the abdomen }\end{array}$ & Freely perforated viscus \\
Pneumonia & $\begin{array}{l}\text { Intratracheal injection or inhalation of a bacterial } \\
\text { inoculum }\end{array}$ & Pneumonia \\
Urosepsis & Intravesical injection of a bacteria inoculum & Urosepsis from ascending urinary tract infection \\
\hline
\end{tabular}




\section{Table 2}

The Murine Sepsis Score (MSS) to assess animal response to abdominal sepsis models

\begin{tabular}{|c|c|}
\hline Variable & Score and Description \\
\hline \multirow[t]{5}{*}{ Appearance } & $0-$ Coat is smooth \\
\hline & 1 - Patches of hair piloerected \\
\hline & 2 - Majority of back is piloerected \\
\hline & 3 - Piloerection may or may not be present, mouse appears "puffy" \\
\hline & 4 - Piloerection may or may not be present, mouse appears emaciated \\
\hline \multirow[t]{5}{*}{ Level of consciousness } & $0-$ Mouse is active \\
\hline & 1 - Mouse is active but avoids standing upright \\
\hline & 2 - Mouse activity is noticeably slowed. The mouse is still ambulant \\
\hline & 3 - Activity is impaired. Mouse only moves when provoked, movements have a tremor \\
\hline & 4 - Activity severely impaired. Mouse remains stationary when provoked, with possible tremor. \\
\hline \multirow[t]{5}{*}{ Activity } & $0-$ Normal amount of activity. Mouse is any of: eating, drinking, climbing, running, fighting \\
\hline & 1 - Slightly suppressed activity. Mouse is moving around bottom of cage \\
\hline & 2 - Suppressed activity. Mouse is stationary with occasional investigative movements \\
\hline & 3 - No activity. Mouse is stationary \\
\hline & 4 - No activity. Mouse experiencing tremors, particularly in the hind legs \\
\hline \multirow[t]{5}{*}{ Response to stimulus } & 0 - Mouse responds immediately to auditory stimulus or touch \\
\hline & 1 - Slow or no response to auditory stimulus; strong response to touch (moves to escape) \\
\hline & 2 - No response to auditory stimulus; moderate response to touch (moves a few steps) \\
\hline & 3 - No response to auditory stimulus; mild response to touch (no locomotion). \\
\hline & 4 - No response to auditory stimulus. Little or no response to touch. Cannot right itself if pushed over \\
\hline \multirow[t]{5}{*}{ Eyes } & $0-$ Open \\
\hline & 1 - Eyes not fully open, possibly with secretions \\
\hline & 2 - Eyes at least half closed, possibly with secretions \\
\hline & 3 - Eyes half closed or more, possibly with secretions \\
\hline & $4-$ Eyes closed or milky \\
\hline \multirow[t]{5}{*}{ Respiration rate } & 0 - Normal, rapid mouse respiration \\
\hline & 1 - Slight decreased respiration (rate not quantifiable by eye) \\
\hline & 2 - Moderately reduced respiration (rate at the upper range of quantifying by eye) \\
\hline & 3 - Severely reduced respiration (rate easily countable by eye, $0.5 \mathrm{~s}$ between breaths) \\
\hline & 4 - Extremely reduced respiration (>1 s between breaths) \\
\hline \multirow[t]{5}{*}{ Respiration quality } & $0-$ Normal \\
\hline & 1 - Brief periods of labored breathing \\
\hline & 2 - Labored, no gasping \\
\hline & 3 - Labored with intermittent gasps \\
\hline & 4 - Gasping \\
\hline
\end{tabular}

From: Shrum B, Anantha R V, Xu SX, et al.: A robust scoring system to evaluate sepsis severity in an animal model. BMC Res Notes 2014; $7: 233$. 


\section{Table 3}

\section{Comparison of the CONSORT and ARRIVE guidelines}

\begin{tabular}{|c|c|}
\hline CONSORT & ARRIVE \\
\hline Title and abstract & Title and abstract \\
\hline Introduction & Introduction \\
\hline Background and objectives & Background and objectives \\
\hline Methods & Methods \\
\hline Trial design & Study design \\
\hline Participants & Experimental animals \\
\hline Interventions & Experimental procedures \\
\hline \multicolumn{2}{|l|}{ Outcomes } \\
\hline Sample size & Sample size \\
\hline \multicolumn{2}{|c|}{ Randomization sequence generation } \\
\hline Allocation concealment & Allocation of animals to experimental groups \\
\hline \multicolumn{2}{|l|}{ Randomization implementation } \\
\hline \multicolumn{2}{|l|}{ Blinding } \\
\hline \multirow[t]{3}{*}{ Statistical methods } & Statistical methods \\
\hline & Housing and husbandry \\
\hline & Ethical statement \\
\hline Results & Results \\
\hline \multicolumn{2}{|l|}{ Participant flow diagram } \\
\hline \multicolumn{2}{|l|}{ Recruitment } \\
\hline Baseline data & Baseline data \\
\hline Numbers analyzed & Numbers analyzed \\
\hline Outcomes and estimation & Outcomes and estimation \\
\hline \multicolumn{2}{|l|}{ Ancillary analyses } \\
\hline Harms & Adverse events \\
\hline Discussion & Discussion \\
\hline Limitations & Interpretation and scientific implications (including limitations) \\
\hline Generalizability Interpretation & Generalizability/translation \\
\hline \multicolumn{2}{|l|}{ Other Information } \\
\hline \multicolumn{2}{|l|}{ Trial registration } \\
\hline \multicolumn{2}{|c|}{ Location of full protocol description } \\
\hline Funding source(s) & Funding source(s) \\
\hline
\end{tabular}

